\title{
Epidemiological and histopathological study of thyroid lesions in a tertiary care hospital in south India
}

\author{
Chandana A. ${ }^{1}$, Gomathi R. ${ }^{2 *}$, Prakashiny S. ${ }^{3}$ \\ DOI: https://doi.org/10.17511/jopm.2020.i06.03 \\ ${ }^{1}$ Adayalam Chandana, Assistant Professor, Department of Pathology, Sri Balaji Vidyapeeth Deemed to be University, Kancheepuram, Tamil \\ Nadu, India. \\ 2* Gomathi R., Associate Professor, Department of Pathology, Sri Balaji Vidyapeeth Deemed to be University, Kancheepuram, Tamil Nadu, \\ India. \\ 3 Prakashiny S., Assistant Professor, Department of Pathology, Sri Balaji Vidyapeeth Deemed to be University, Kancheepuram, Tamil Nadu, \\ India.
}

Introduction: Thyroid swellings are easily picked up on general physical examination. Due to various cosmetic concerns, there has been a steady increase in thyroid surgeries in recent years. Many epidemiological risk factors have been attributed to the development of various thyroid lesions and malignancies. The present study was carried out to evaluate the epidemiology and histopathological distribution of various thyroid lesions. Material and Methods: This cross-sectional study was carried out among 130 patients presenting with visible thyroid swelling to our tertiary care institution. The post-operative specimens of the thyroid were fixed in $10 \%$ formalin, processed,

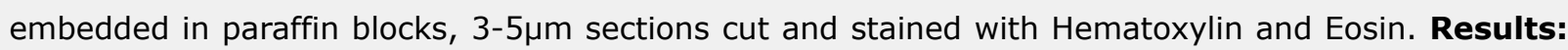
Out of the 152 cases of thyroid lesions analyzed, 12 (7.9\%) were simple goiter, 15(9.9\%) were multinodular goiter, 47 (30.9\%) were adenomas, 52 (34.2\%) were papillary carcinomas, $1(0.6 \%)$ was medullary carcinoma. About $96 \%$ of the participants had a positive dietary history, $50 \%$ of them had a positive family history. Papillary carcinoma and its variants were the most commonly diagnosed lesion accounting for about $34.2 \%$ of the cases. Conclusion: Thyroid biopsy rates are on the rise because of increased awareness. Therefore, the detection of thyroid malignancies is also on the rise. The diagnosis and management of thyroid tumors require a collective outlook on the part of the clinician and pathologist. Despite advances in imaging technology pathologists' role is very important in the diagnosis of thyroid neoplasms and in predicting the prognosis and patient outcome.

Keywords: Thyroid malignancy; Microscopic variants, Papillary carcinoma, Thyroid nodules

\section{Corresponding Author}

Gomathi R., Associate Professor, Department of Pathology, Sri Balaji Vidyapeeth Deemed to be University, Kancheepuram, Tamil Nadu, India. Email: goms318@gmail.com

\section{How to Cite this Article}

Chandana A, Gomathi R, Prakashiny S. Epidemiological and histopathological study of thyroid lesions in a tertiary care hospital in south India. Trop J Pathol Microbiol. 2020;6(6):381-386. Available From

https://pathology.medresearch.in/index.php/jopm/ar ticle/view/468
To Browse

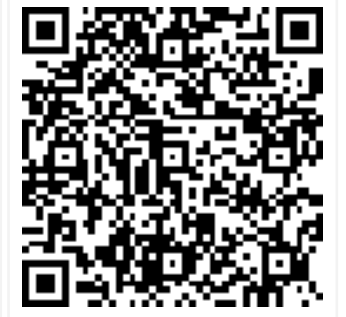

Manuscript Received 2020-07-02

Conflict of Interest No
Review Round 1 2020-07-31

Funding

Nil

Review Round 2
2020-08-13
$\begin{gathered}\text { Ethical Approval } \\ \text { Yes }\end{gathered}$

Review Round 3

Plagiarism X-checker $4 \%$
Accepted 2020-08-26

Note

(C) 2020 by Adayalam Chandana, Gomathi R., Prakashiny S. and Published by Siddharth Health Research and Social Welfare Society. This is an Open Access article licensed under a Creative Commons Attribution 4.0 International License https://creativecommons.org/licenses/by/4.0/ unported [CC BY 4.0]. 


\section{Introduction}

The thyroid gland is unique among the endocrine glands in manifesting with a wide spectrum of diseases ranging from functional enlargements and immunologically mediated enlargements to neoplastic lesions. These enlargements may be diffuse or nodular at times causing obvious physiological changes. In contrast, patients having a papillary carcinoma thyroid with lymph node secondaries may present with obvious metastatic disease with an undetectable primary (occult or hidden malignancy of thyroid). According to recent studies, the prevalence of thyroid nodules in India was $12.2 \%$ although the incidence of thyroid malignancies is far lesser, about 8.7 per 100,000 population $[1,2]$.

Radiation and genetics are two important causal factors of thyroid cancers. Radiation causes mutations that can be carcinogenic. Exposure to ionizing radiation is a well-documented risk factor for thyroid cancer. The thyroid may be irradiated more than other tissues because of its position in the body and its ability to concentrate iodine. Exposure to radiation has inadvertently increased in recent years due to medical and dental diagnostic examinations which have specifically increased thyroid exposure to X-rays [2]. Computerized Tomography (CT) scans, although accounting for only $15 \%$ of all radiological diagnostic procedures, provide more than $50 \%$ of the radiation dose absorbed by patients [3].

The thyroid is extremely radiosensitive in children. Children exposed to radiation frequently develop papillary thyroid cancer (PTC). The role of CT scans in increasing the risk of cancer in children is already documented: CT scans delivering a cumulative dose of 50-60 mGy almost triple the risk of leukemia and brain cancer [4]. Another specific source of thyroid irradiation is thyroid imaging with 131I that has been largely used for the diagnosis of thyroid diseases. Thyroid scans constituted up to $13 \%$ of all nuclear medicine examinations worldwide a few decades back and thereafter decreased to the present rate of less than $1 \%$ with 131I substituted by the less-dangerous [5].

Iodine deficiency causes an increase in the secretion of thyroid-stimulating hormone (TSH), a major growth factor for thyroid follicular cells. Iodine intake is known to influence the thyroid cancer histotype distribution, rather than the overall incidence, with more follicular and fewer papillary
Carcinomas in iodine-deficient areas [6]. When iodine prophylaxis was introduced, the average serum TSH decreases, and the papillary: follicular ratio increases. The iodine-associated shift from a follicular to a papillary histotype may be due to the frequency of the $\operatorname{BRAF}(\mathrm{V} 600 \mathrm{E})$ mutation, a typical molecular alteration in PTC $[7,8]$. Although a causal relationship between iodine intake and BRAF mutation is not proven, the worldwide increase of iodine intake and the parallel increase in the prevalence of BRAF-positive PTCs is in agreement with a possible role of increased iodine intake in the increased PTC incidence [9].

In addition to radioactive iodine, dietetic factors that interfere with iodine organification and thyroid hormone synthesis, such as cruciferous vegetables, could also affect thyroid cancer risk [10].

With the growing prevalence of thyroid disorders in India, there is a need to document the epidemiology and risk factors of thyroid nodules, in the light of malignancies. A detailed histopathological correlation with epidemiology, in a hospital setting, will give deeper insights into the pattern of presentation and will therefore be helpful in planning preventive strategies to combat thyroid disorders at the community level.

\section{Objectives}

The present study was carried out to

01. Assess the epidemiology and pattern of presentation of thyroid nodules

02. Evaluate the histopathological variants of thyroid nodules.

\section{Methodology}

Study setting: The study was carried out in a tertiary care center in South India.

Inclusion Criteria: All the patients presenting to Gen. Surgery department with thyroid abnormalities and undergoing a hemithyroidectomy or total thyroidectomy procedure.

Ethical approval: Approval was obtained from the Institutional Ethics Committee prior to the commencement of the study.

Data analysis: Data was entered and analyzed using Microsoft Excel spreadsheet 2010. The epidemiological parameters of thyroid nodules were expressed as percentages. Histopathological grading was also expressed in percentages. 


\section{Results}

A total of 152 excision biopsy specimens of thyroid nodules were analyzed in this study. The background characteristics of the study participants are given in Figure 1 . The majority of the participants were aged between 21-30 years $(31.5 \%)$ followed by $31-40$ years $(30.6 \%)$. About $92.8 \%$ of the participants were females.

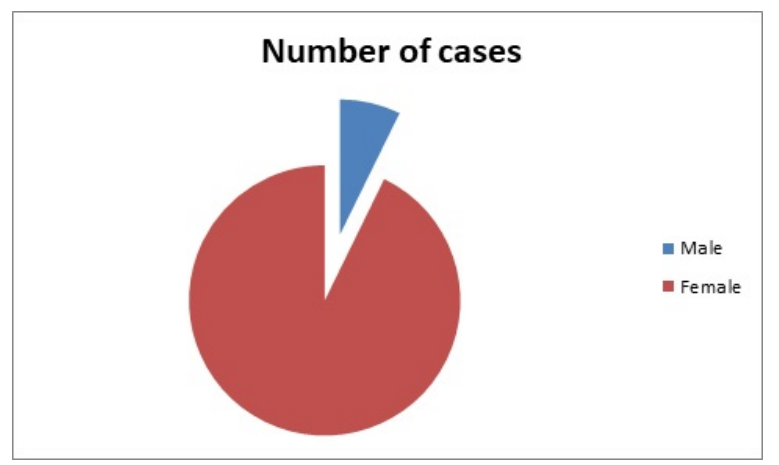

Fig-1: Gender distribution of thyroid lesions.

$92.8 \%$ were Females; $7.2 \%$ were Males.

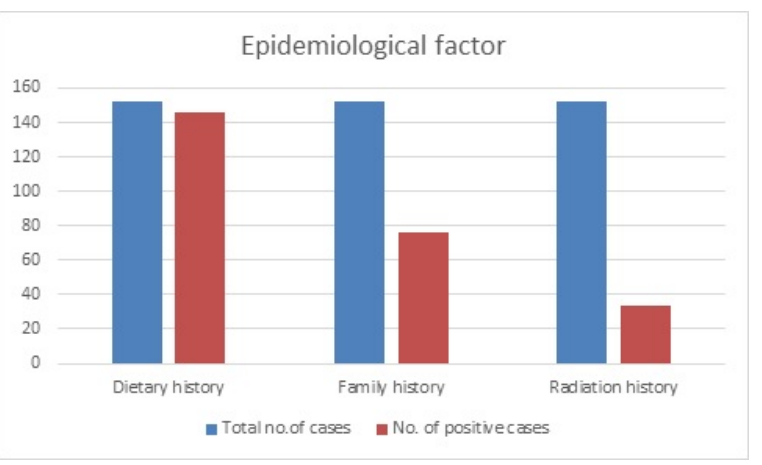

Fig-2: Epidemiological risk factors of thyroid disorders among the study participants.

$96.05 \%$ had a positive dietary history; $50 \%$ had a positive family history; $22.36 \%$ had a positive radiation history. The epidemiological risk factors of thyroid disorders among the study participants are given in Figure 2. The majority of the participants (96.05\%) had a positive diet history, while $50 \%$ of them had a positive family history. About $22.4 \%$ of the participants had a positive history of radiation exposure. In this study, the majority of the specimens were positive for neoplasm (65.8\%), and $34.3 \%$ of the participants showed non-neoplastic lesions. Among the non-neoplastic lesions, the majority of the specimens showed Hashimoto's thyroiditis (46.2\%) followed by multinodular goiter (28.9\%). Among the neoplastic lesions, the majority
Of the tumors were malignant (53\%) (Table 1 ).

Table-1: Distribution of thyroid lesions based on neoplasms.

\begin{tabular}{|c|c|c|c|c|}
\hline $\begin{array}{l}\text { SI. } \\
\text { No }\end{array}$ & \multicolumn{2}{|c|}{ Thyroid lesions } & $\begin{array}{c}\text { Number of } \\
\text { cases }\end{array}$ & Percentage \\
\hline \multirow[t]{4}{*}{1} & \multirow{4}{*}{$\begin{array}{l}\text { Non- } \\
\text { neoplastic }\end{array}$} & Simple Goitre & 12 & 7.89 \\
\hline & & Multinodular goiter & 15 & 9.87 \\
\hline & & $\begin{array}{l}\text { Hashimoto's } \\
\text { thyroiditis }\end{array}$ & 24 & 15.79 \\
\hline & & $\begin{array}{l}\text { Lymphocytic } \\
\text { thyroiditis }\end{array}$ & 1 & 0.66 \\
\hline \multirow[t]{2}{*}{2} & \multirow[t]{2}{*}{ Neoplastic } & Benign tumors & 47 & 30.92 \\
\hline & & Malignant tumors & 53 & 34.87 \\
\hline \multicolumn{3}{|l|}{ Total } & 152 & 100 \\
\hline
\end{tabular}

The age-wise distribution of these tumors revealed that the majority of the non-neoplastic lesions presented in the age group of $21-30$ years $(30.7 \%)$ whereas benign and malignant thyroid lesions presented predominantly in the age group of 31-40 years (29.7\% and $37.7 \%$ respectively) (Figure 3 ). Among the malignant tumors of the thyroid, $98.1 \%$ were papillary carcinoma; $1.8 \%$ were medullary carcinoma. (Figure 4).

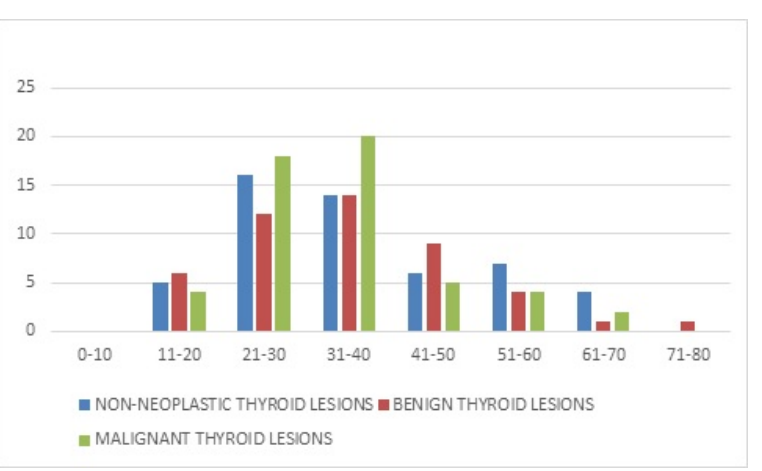

Fig-3: Age-wise distribution of thyroid lesions.

$45.5 \%$ were benign; $54.5 \%$ were malignant.

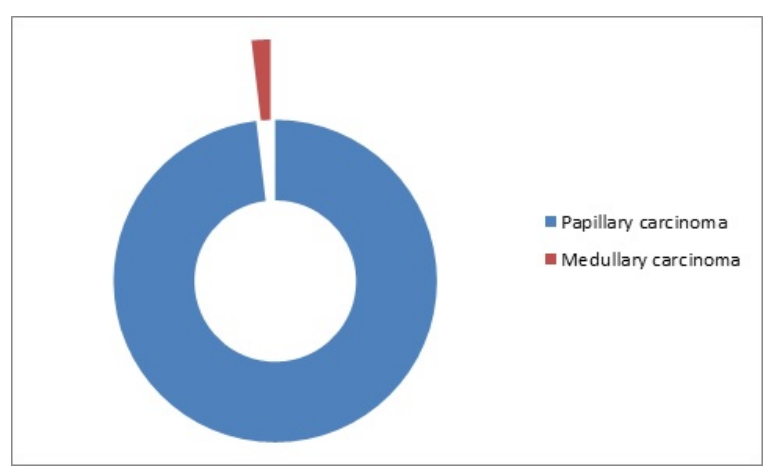

Fig-4: Distribution of Malignant Thyroid Lesions. 
$98.1 \%$ were papillary carcinoma; $1.8 \%$ were medullary carcinoma.

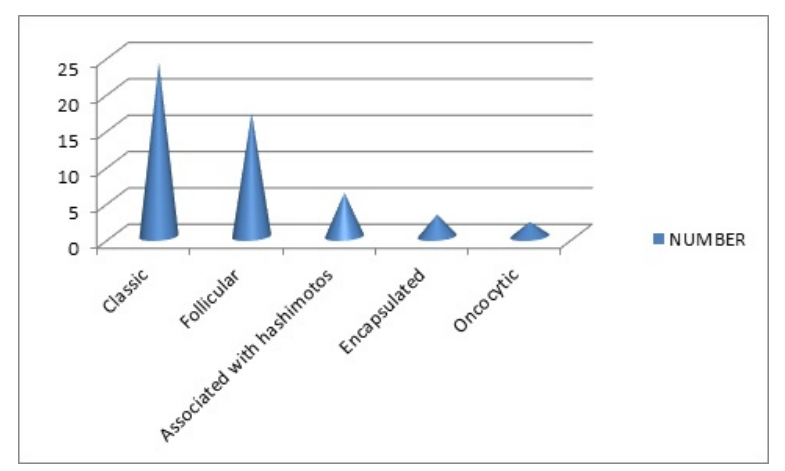

\section{Fig-5: Microscopic Variants of Papillary Thyroid Carcinoma.}

Majority of them were classical papillary carcinomas The microscopic variants of papillary carcinoma consisted predominantly of classic type (46.1\%) followed by follicular type (32.6\%). In $11.5 \%$ of the participants, the papillary carcinoma was found to be associated with Hashimoto's thyroiditis (Figure 5). Microscopically, the Classical variant of Papillary Carcinoma Thyroid showed central fibrovascular core with optical clear (Orphan Annie eye) nuclei. (Figure 6 and 7).

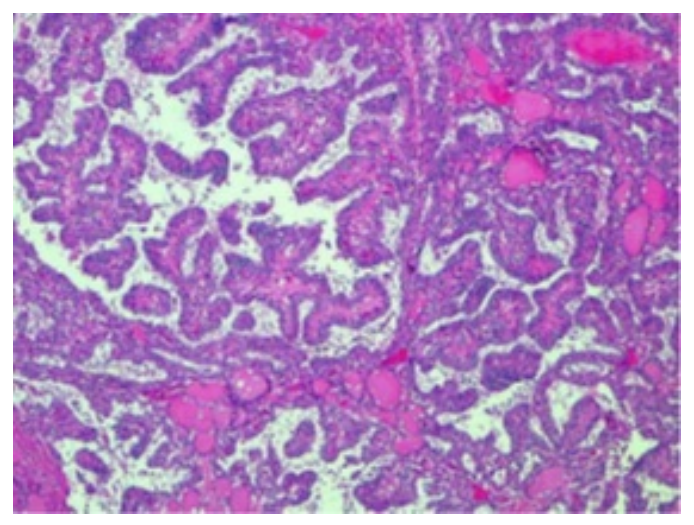

10x View, $H$, and E Stain -Papillary carcinoma classic variant

\section{Fig-6: Classical Variant of Papillary Thyroid Carcinoma.}

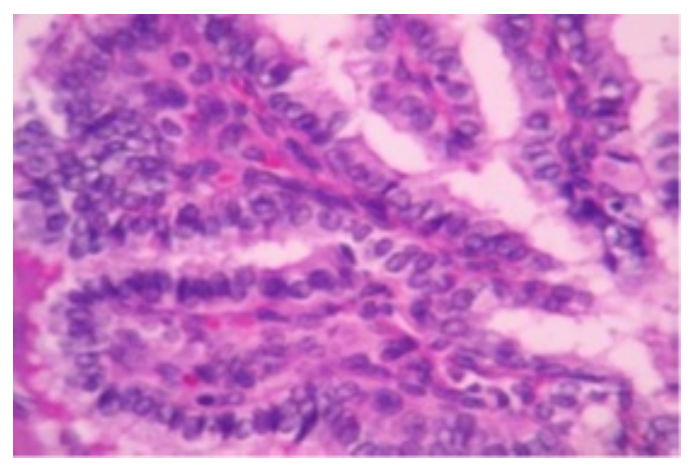

$\mathrm{H}$ and $\mathrm{E} 40 \mathrm{X}$ view-Microscopic picture of papillary carcinoma showing complex branching pattern with fibrovascular core (Arrow showing Orphan Annie Eye nuclei.)

\section{Fig-7: Classical Variant of Papillary Thyroid Carcinoma.}

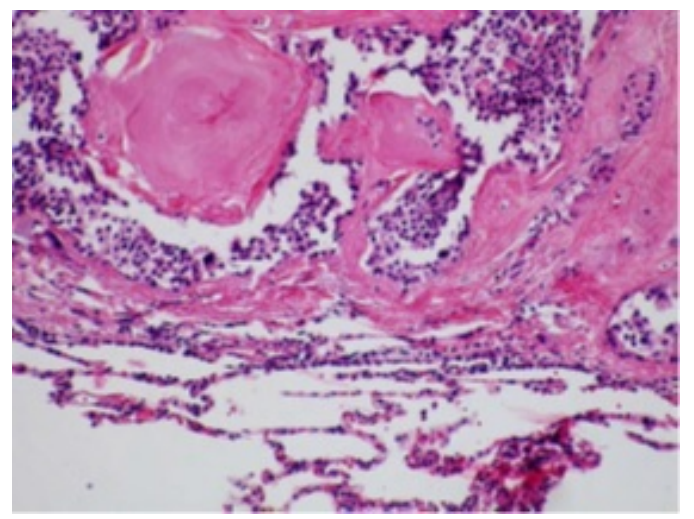

$\mathrm{H}$ and $\mathrm{E}$ 40Xview: Medullary Carcinoma -Arrow showing extracellular deposition of homogenous acellular pink material

\section{Fig-8: Medullary Carcinoma Thyroid.}

Among all the malignant tumors of the thyroid, there were $1.8 \%$ of Medullary carcinoma thyroid, with microscopical features of extracellular homogenous pink acellular material (Amyloid deposits) (Figure-8).

\section{Discussion}

Thyroid disorders are significantly emerging as a major endocrine disorder among women, especially in the young and reproductive age group. Chronic, uncorrected thyroid disorders pose serious complications ranging from infertility to cardiovascular abnormalities. Among the various thyroid disorders, palpable thyroid swellings require adequate care and evaluation due to its malignant potential. Although these nodules are often detected at earlier staged due to cosmetic discomfort, it is essential to evaluate them for risk factors in order to prevent their incidence in the forthcoming populations.

The present study was carried out among 152 resected thyroid nodule specimens received in the Department of Pathology for a period of two years. The majority of the participants were females and belonged to the age group of 21-40 years. A study was done by Srinivas $\mathrm{KV}$ et al also consisted of a similar population group with a mean age of 35 years, similar to the present study. Another study 
Done by Gupta $M$ et al was done in a similar age group with a mean age of 37 years, similar to the present study. The thyroid nodules in the present study were predominantly observed among females, with a male-female sex ratio of $1: 12.8$. Studies were done by Srinivas MNS [13] and Gupta M [14] showed similar findings (1:9 and $1: 11$ respectively). In a study by Prabha et al, thyroid diseases showed definite female predominance, with most of them occurring in an age group of 31-40 years. [16]

The pattern of presentation of thyroid nodules has revealed that the majority of the lesions are neoplastic, and the ratio of non-neoplastic versus neoplastic tumors in the present study was $0.52: 1$. ratio. However, most of the literature shows more non-neoplastic lesions compared to the neoplastic types. This increasing presentation of neoplastic lesions in the present study needs further evaluation of the community for the presence of endemicity of thyroid disorders.

Overall, the present study has documented an increased prevalence of papillary carcinoma followed by follicular neoplasm and nodular/colloid goiter. In the study done by SrinivasMNS [13], nodular/colloid goiter was the most predominant, followed by Hashimoto's/ lymphocytic thyroiditis. In the study done by Gupta M [14], the follicular neoplasm was the most common diagnosis, second next to nodular/colloid goiter.

The present study has documented a significant prevalence of diet history and family history among the study participants. This gives an insight into the potential risk of endemicity of thyroid malignancies in the study area, warranting significant public health response.

Presence of widespread community prevalence of thyroid lesions, complimented with a significant diet history and family history strongly suggestive of thyroid malignancies, there is an imminent need for a large based public health response to carry out the evaluation of the cause of this growing prevalence of thyroid malignancies. Moreover, effective preventive strategies for early detection are also required to create awareness among the general public regarding the clinical manifestations and preventive actions.

Thyroid biopsy rates are on the rise because of increased awareness among our population brought about by much publicizing by the popular media. So the detection of thyroid malignancies is also on the rise. Many thyroid malignancies arise in the back-
Ground of pre-existing thyroid disease. Microscopic patterns in these lesions differ from case to case and prognosis differs accordingly. So careful and accurate histopathological typing of thyroid malignancies has important clinical implications for the patient. The diagnosis and management of thyroid tumors require a collective outlook on the part of the clinician and pathologist. Thyroid enlargement is usually silent unless noticed for cosmetic reasons or if it produces pressure symptoms. It is difficult to differentiate clinically a benign lesion from a malignant one clinically unless the tumor shows signs of infiltration. In such cases, histopathological examination helps the clinician to arrive at a correct diagnosis and to proceed with further management. Despite advances in imaging technology pathologists' role is very important in the diagnosis of thyroid neoplasms and in predicting the prognosis and patient outcome [15].

\section{Limitations}

An immunohistochemistry marker study was not done for the variants of thyroid malignancies. That would have given us a detailed list of variants of papillary carcinoma thyroid and their epidemiological correlation.

\section{Conclusion}

The present study was carried out to evaluate the epidemiological presentation of thyroid nodules and their histopathological pattern of presentation. The current study has shown a significant prevalence of thyroid neoplasms, especially papillary carcinoma. Moreover, the lesions are predominantly affecting the women of younger age group between 20-40 years, which is the prime reproductive age group.

\section{What does the study add to the existing knowledge}

This study confirms that the study area is a belt for thyroid malignancies. Thyroid malignancies can occur in patients as young as 19years with positive family history and radiation history.

\section{Author's contribution}

\section{Dr. Adayalam Chandana: Literature review}

Dr. Gomathi. R.: Statistical analysis and manuscript preparation

Dr. Prakashiny S.: Sample collection 


\section{Reference}

01. Unnikrishnan AG, Kalra S, Baruah M. Endocrine society of India management guidelines for patients with thyroid nodules- A position statement. Indian J Endocrinol Metab. $2011 ; 15(1) 2-8$.

doi: $10.4103 / 2230-8210.77566$ [Crossref]

02. Mettler FAJR, Wiest PW, Locken JA. CT scanningpatterns of use and dose. J Radiol Prot. $2000 ; 20(4) 353-359$.

doi: $10.1088 / 0952-4746 / 20 / 4 / 301 \quad$ [Crossref]

03. Linton OW, Mettler FA, Locken JA. National conference on dose reduction in $\mathrm{CT}$, with an emphasis on pediatric patients. Am J Roentgenol. 2003;181(2)321-329. doi: 10.2214/ajr.181.2.1810321 [Crossref]

04. Pearce MS, Salotti JA, Little MP, Hugh KM. Radiation exposure from CT scans in childhood and subsequent risk of leukaemia and brain tumours- a retrospective cohort study. The Lancet. 2012;380(9840)499-505.

doi: $10.1016 /$ S0140-6736(12)60815-0 [Crossref]

05. Ron E. Cancer risks from medical radiation. Health Physics. 2003;85(1)47-59.

doi: 10.1097/00004032-200307000-00011 [Crossref]

06. Dijkstra B, Prichard RS, Lee A, Smyth PPA, Crotty T. Changing patterns of thyroid carcinoma. Irish J Med Sci. 2007;176(2)87-90.

doi: $\quad 10.1007 / s 11845-007-0041-y \quad$ [Crossref]

07. Harach, HR, Escalante DA, Onativia, A, Lederer Outes J, Saravia Day E, Williams ED. Thyroid carcinoma and thyroiditis in an endemic goitre region before and after iodine prophylaxis. Acta Endocrinologica. 1985;108(1)55-60.

doi: 10.1530/acta.0.1080055 [Crossref]

08. Peterson E, De P, Nuttall R. BMI, diet and female reproductive factors as risks for thyroid cancera systematic review. PLoS One. 2012;7(1)5476.

doi: 10.1371/journal.pone.0029177 [Crossref]
01. Mathur A, Moses W, Rahbari, R, Khanafshar E, Duh QY, Clark O, et al. Higher rate of BRAF mutation in papillary thyroid cancer over time- a single-institution study. Cancer. 2011;117(19)4390-4395.

doi: $10.1002 /$ cncr.26072 [Crossref]

02. Feildt-rasmussem U. Iodine and cancer. Thyroid. $2001 ; 11(5) 483-486$.

doi: $10.1089 / 105072501300176435$ [Crossref]

03. Bichoo R, Mishra A, Kumari N. Poorly Differentiated Thyroid Carcinoma and Poorly Differentiated Area in Differentiated Thyroid Carcinoma- Is There Any Difference?. Langenbecks Arch Surg. 2019;404(1)45-53.

doi: $10.1007 / \mathrm{s} 00423-019-01753-6$ []

04. Hedinger C, Williams D, Sobin LH. The WHO histological classification of thyroid tumors-A commentary on the 2nd edition. Cancer. $1989 ; 63(2) 908-911$.

doi: $10.1002 / 1097-0142(19890301) 63: 5<908:$ :AIDCNCR2820630520>3.0.CO;2-I [Crossref]

05. Srinivas MN, Amogh VN, Gautam MS, Prathyusha IS, Vikram NR, Retnam MK, et al. A prospective study to evaluate the reliability of thyroid imaging reporting and data system in differentiation between benign and malignant thyroid lesions. J Clin Imaging Sci. 2016;6(5)908-911.

doi: $10.4103 / 2156-7514.177551$ [Crossref]

06. Gupta M, Gupta S, Gupta VB. Correlation of Fine Needle Aspiration Cytology with Histopathology in the Diagnosis of Solitary Thyroid Nodule. J Thyroid Res. 2010;45(2)1-5.

doi: $10.4061 / 2010 / 379051$ [Crossref]

07. Rafla S. Anaplastic tumors of the thyroid. Cancer. 1969;23(1)657-668.

doi: $\quad 10.1002 / 1097-0142(196903) 23: 3<668:$ :AIDCNCR2820230321>3.0.CO;2-8 [Crossref]

08. Prabha V, Bhuvaneswari MG. Study of Histopathological Spectrum of Thyroid LesionsAn Observational Study. Int J Sci Stud. 2019;7(1)1-4.

Available from [Article] [Crossref] 